\title{
Irrigation Cut-off Date Affects Growth, Frost Damage, and Yield of Jojoba
}

\author{
John M. Nelson ${ }^{1}$, David A. Palzkill ${ }^{2}$, and Paul G. Bartels \\ Department of Plant Sciences, University of Arizona, Tucson, AZ 85721
}

Additional index words. Simmondsia chinensis, seed yield, wax, water stress, new crops

\begin{abstract}
Flower bud injury resulting from freezing temperatures has been a major problem in jojoba [Simmondsia chinensis (Link) C. Schneid.] production. A 3-year field study, which began with 4-year-old plants, evaluated the effect of three irrigation treatments on growth, flower bud survival, seed yield, seed weight, and seed wax concentration of six clones. After 3 years, irrigation cut-off dates of late May (dry treatment) and early September (medium treatment) resulted in reduced plant height and width compared to irrigating through November (wet treatment). Flower bud survival and seed yields were very low in the first year for all treatments. In the second and third years, bud survival for most clones, even at -8C, was greatly improved by withholding water in the fall. In December of the second and third years, plants in the medium and dry plots had lower leaf water potential than those in the wet plot. In the second year, plants in the medium and dry plots had seed yields that were 3.5 times higher and wax yields that were were 2.3 times higher than plants in the wet plot. In the third year, the medium treatment had the highest seed and wax yields. Average seed weight and seed wax concentration were generally highest for plants in the wet plot where seed yields were low. Withholding irrigation from jojoba in the fall appears to improve flower bud survival and seed and wax yields following cold winters.
\end{abstract}

Jojoba is a new industrial crop being grown commercially in hot arid and semiarid regions of the southwestern United States. The primary product of this evergreen shrub is a unique liquid wax contained in the seed. This wax is used as a natural base for a wide range of cosmetic products, has heat-resistant lubricating properties, and is potentially useful in the chemical industry.

Several factors limiting jojoba production have become apparent, including the use of low-yielding genotypes, cold injury to flower buds, and a lack of information on suitable cultural practices. Most of the early plantations were established from seed or seedlings collected from female plants in the wild, and these populations typically have a low percentage of high seed producers (Yermanos, 1983). This problem is being overcome to some extent by using cuttings from plants with high-yield potential to upgrade older plantations and establish new ones (Hogan and Palzkill, 1983).

Freezing temperatures are a major environmental constraint to jojoba cultivation in the United States. Flower buds are produced on the current season's growth and usually open the following spring. Winter temperatures in the -3 to $-5 \mathrm{C}$ range generally kill flower buds (Dunstone, 1988). Although the jojoba-growing regions of the southwestern United States have warm climates, most are subject to episodic freezes. Cultural factors appear to affect the susceptibility of flower buds to frost damage. Yermanos (1983) found that supplemental irrigation reduced jojoba yields in cold years, and he attributed this to the extra water, which maintains the flower buds in a more frost-sensitive state. Mild water stress has increased the tolerance of jojoba leaves and floral buds to freezing temperatures in greenhouse and laboratory studies (Ceccardi et al., 1990; Naqvi et al., 1988).

Currently, many growers terminate irrigation early to induce water stress in their jojoba plants before winter. Field data are lacking, however, on the benefits of using irrigation management to reduce frost injury. If this practice is to become part of a

Received for publication 13 July 1992. Accepted for publication 16 Feb. 1993. The cost of publishing this paper was defrayed in part by the payment of page charges. Under postal regulations, this paper therefore must be hereby marked advertisement solely to indicate this fact.

${ }^{1}$ To whom reprint requests should be addressed.

${ }^{2}$ Former Assistant Professor. Present address: 2801 N. Sparkman, Tucson, AZ 85716. management system, more information is needed to determine when to curtail irrigation. This study's objective was to determine the effect of irrigation cut-off dates on jojoba growth, flower bud survival in the winter, and seed yield during the subsequent growing season.

\section{Materials and Methods}

The study was conducted from Mar. 1988 to Aug. 1991 at the Univ. of Arizona Maricopa Agricultural Center, Maricopa, Ariz., in a planting established in 1984 from rooted cuttings. This site was selected because it has damaging frosts in most years. The soil type is Casa Grande sandy loam (fine-loamy, mixed, hyperthermic Typic Natrargid). The planting contained six female clones designated as $01,03,04,06,15$, and 21; plant spacing was $1.2 \mathrm{~m}$, and row spacing was $4.1 \mathrm{~m}$. The clones were selected from a germplasm nursery established in Bakersfield, Calif., in 1979 and 1980. Clone 01 has been released by the Univ. of Arizona as clone AT1487 (Palzkill et al., 1989). Every sixth plant in each row was a male.

The field in Maricopa was flood-irrigated from the transplant date until March 1988, when three irrigation treatments were established (Table 1). The wet treatment (WT) used a drip system to provide water based on estimated seasonal evapotranspiration. The medium (MT) and dry (DT) treatments used flood irrigation at $115 \mathrm{~mm}$ of water per application. The study was continued

Table 1. Irrigation treatments during 1988-90. Irrigation treatments were continued through July 1991 to mature the 1990-91 seed crop. Treatments were the same as in 1990, except that the medium and dry plots received an additional irrigation in June.

\begin{tabular}{llcccr}
\hline \hline & & \multicolumn{3}{c}{$\begin{array}{c}\text { Total water } \\
\text { (irrigation + rain) }\end{array}$} \\
& Irrigation & $\begin{array}{c}\text { Irrigations } \\
(\mathrm{mm})^{\mathrm{z}}\end{array}$ \\
\cline { 3 - 6 } Treatment & schedule & (no./yr) & 1988 & 1989 & 1990 \\
\hline Wet & Mar. to Nov. (biweekly) & 20 & $529^{y}$ & 647 & 1064 \\
Medium & Mar., May, July, Sept. & 4 & 621 & 559 & 692 \\
Dry & Mar. and May & 2 & 391 & 329 & 462
\end{tabular}

zRainfall was 161,99 , and $232 \mathrm{~mm}$ in 1988, 1989, and 1990, respectively. yThe drip system supplied less water than was intended. 
through July 1991 to obtain seed from flower buds produced in 1990. Irrigation treatments were the same in 1990 and 1991, except that medium and dry plots received an additional $115 \mathrm{~mm}$ of water on 27 June 1991. Each irrigation plot contained three rows of plants divided into subplots of 15 female plants of each clone. In May 1987, the planting received $75 \mathrm{~kg} \mathrm{~N} / \mathrm{ha}(46 \mathrm{~N}-0 \mathrm{P}-0 \mathrm{~K})$ from a broadcast application of urea. The design was a split plot in randomized complete blocks with main plots replicated four times.

Plant height and width measurements were taken on four plants of each clone for each irrigation plot in Apr., July, Sept., and Nov. 1988, 1989, and 1990. In Nov. 1989 and 1990, we tagged four branches on the upper canopy of two plants per clone in each irrigation plot, and we recorded the number of flower buds for each branch. We determined bud survival in April by counting buds that flowered on tagged branches.

In July and Aug. 1990 and 1991, seed was hand-harvested from two plants per clone in each irrigation plot. The seeds were air dried, cleaned, and weighed. Seed wax concentration was determined by a nondestructive nuclear magnetic resonance technique using a Newport MK111A analyzer (Newport Instruments, Blakelands North, Milton Keynes, Bucks., U.K.).

Two plants each of clones 01 and 15 were sampled per plot from three replicates for water potential determination in Winter 1990 and 1991. Only two of the six clones were selected for study because of limited equipment. Discs from fully expanded leaf blades at the second or third node from the shoot tip were collected weekly between 1000 and 1100 HR from 1 Nov. to 26 Dec. 1990 and on 3 Dec. 1991. Leaf disc water potentials were measured with Merrill 75-11CW psychrometric chambers (J.R.D. Merrill Specialty Equipment, Logan, Utah) and a Wescor HP-115 water potential data system microprocessor (Wescor, Logan, Utah).

\section{Results and Discussion}

Growth. In 1988, MT resulted in significantly more growth than DT, but there were no differences in growth between these treatments and WT (Table 2). WT plants did not grow as rapidly as expected and appeared to have water stress during the summer, based on visual observations. The amount of water supplied by drip irrigation to the wet plot may have been insufficient for maximum growth. Plants in this study were grown under flood irrigation before 1988, and it may have taken a year or more for plants to adjust to the drip system. Consequently, we increased the
Table 2. Irrigation effects on growth of jojoba in height and width for 3 years.

\begin{tabular}{|c|c|c|c|c|c|c|c|c|}
\hline \multirow{3}{*}{$\begin{array}{l}\text { Irrigation } \\
\text { treatment }\end{array}$} & \multicolumn{8}{|c|}{ Growth $(\mathrm{cm})^{\mathrm{z}}$} \\
\hline & \multicolumn{2}{|c|}{1988} & \multicolumn{2}{|c|}{1989} & \multicolumn{2}{|c|}{1990} & \multicolumn{2}{|c|}{ Total } \\
\hline & ht & width & ht & width & ht & width & ht & width \\
\hline$\overline{\text { Wet }}$ & $15 \mathrm{ab}^{\mathrm{y}}$ & $16 \mathrm{ab}$ & $28 a$ & $31 \mathrm{ab}$ & $28 \mathrm{a}$ & $46 \mathrm{a}$ & $70 a$ & $93 a$ \\
\hline Medium & $18 \mathrm{a}$ & $20 \mathrm{a}$ & $25 \mathrm{a}$ & $35 a$ & $16 \mathrm{~b}$ & $27 \mathrm{~b}$ & $59 \mathrm{~b}$ & $82 \mathrm{~b}$ \\
\hline Dry & $12 \mathrm{~b}$ & $14 \mathrm{~b}$ & $20 \mathrm{~b}$ & $29 \mathrm{~b}$ & $7 c$ & $15 \mathrm{c}$ & $39 \mathrm{c}$ & $58 \mathrm{c}$ \\
\hline
\end{tabular}

${ }^{\mathrm{z} M e a n s}$ are the average of all clones. There were no significant irrigation $x$ clone interactions for any year.

yMean separation within columns by Student-Newman-Kuels' test, $P \leq$ 0.05 .

amount of water applied to wet plots in each of the following years (Table 1).

In 1989, there were no differences in growth between plants in WT and MT; however, growth in height was less in DT. In 1990, growth in height in MT and DT was reduced $43 \%$ and $75 \%$, respectively, compared to WT (Table 2). For the first time, growth in MT was significantly less than in WT. In the first 2 years of the study, enough water apparently was supplied to give MT plants a growth rate similar to those in WT, but by the third year, these plants had increased in size and had a higher water requirement that may not have been met. Also, MT plants in 1990 had a higher seed yield than those in WT (Table 3), and this also may have contributed to a lower growth rate for plants in MT. Nerd and Benzioni (1985) found that fruit load reduced shoot growth. In 1989 and 1990, DT plants grew very little after July, while plants in WT and MT grew until late in the season (data not shown).

By the end of the 3-year study, plants in MT had grown $16 \%$ and $12 \%$ less in height and width, and those in DT had grown $44 \%$ and $38 \%$ less, respectively, than those in WT. Although there were differences in growth rate among clones, the growth response of all clones to the irrigation treatments was similar (data not shown).

Flower bud survival. We recorded temperatures low enough to injure or kill flower buds every winter during the study period. In Winter 1988-89, -6C or lower was reached on six consecutive nights in December. On two of those nights, 28 and 29 Dec., the minimum was $-8 \mathrm{C}$. Temperatures as low as $-8 \mathrm{C}$ were recorded on 13 Dec. and 16 Feb., during Winter 1989-90. During 23-27 Dec. 1990 , the minima were $-8,-5,-6,-7$, and $-6 \mathrm{C}$, respectively.

Flower bud survival was not measured following Winter 1988-

Table 3. Irrigation effects on seed yield of six jojoba clones in 1990 and 1991.

\begin{tabular}{|c|c|c|c|c|c|c|c|}
\hline \multirow{3}{*}{$\begin{array}{l}\text { Irrigation } \\
\text { treatment }\end{array}$} & \multicolumn{7}{|c|}{ Seed yield (g/plant) } \\
\hline & \multicolumn{6}{|c|}{ Clone } & \multirow[b]{2}{*}{ Mean (g) } \\
\hline & 01 & 03 & 04 & 06 & 15 & 21 & \\
\hline \multicolumn{8}{|c|}{$1990^{2}$} \\
\hline Wet & 168 & 4 & 240 & 204 & 4 & 98 & 120 \\
\hline Medium & 762 & 394 & 256 & 663 & 184 & 250 & 418 \\
\hline Dry & 716 & 369 & 276 & 478 & 400 & 339 & 430 \\
\hline \multicolumn{8}{|c|}{$1991^{y}$} \\
\hline Wet & 177 & 163 & 10 & 62 & 9 & 407 & 138 \\
\hline Medium & 493 & 457 & 400 & 149 & 476 & 727 & 450 \\
\hline Dry & 25 & 175 & 164 & 16 & 186 & 224 & 132 \\
\hline Mean & 232 & 265 & 191 & 76 & 224 & 453 & \\
\hline
\end{tabular}


89 , but visual observations indicated that a high percentage of buds and 2 to $4 \mathrm{~cm}$ of stem near the shoot tips were injured or killed in all plots. All clones in all irrigation treatments experienced flower bud injury during the 1989-90 and 1990-91 winters; however, there were large differences in bud survival among irrigation treatments and among clones (Table 4). In these winters, survival was lowest for plants in WT. Withholding irrigation water from jojoba from May until the next spring (DT) greatly improved bud survival during Winter 1989-90 for these clones when compared to WT. The highest survival generally was obtained in MT following Winter 1990-91. Lower survival than expected in DT in 1991 may be due to reduced shoot growth in this treatment in 1990. In 1990, DT plants had less shoot growth than plants in other treatments (Table 2). Consequently, DT shoots contained fewer flower buds, and these buds were near the edge of the canopy where frost damage generally is most severe.

Flower bud survival for clones varied among years. Only clone 21 had a high survival rate $(65 \%$ to $69 \%)$ in one treatment (dry) after both winters. A high percentage of flower buds of clone 06 in MT and DT appeared to be viable following Winter 1990-91, but many of these buds did not proceed to anthesis; the reason is unknown. Although flower bud survival was not determined for male clones, field observations indicated MT and DT had the same effect on survival of male buds as on female ones.

Plants in treatments with the highest flower bud survival exhibited foliar water stress symptoms in Winter 1989-90 and 1990-91. Water-potential measurements in Nov. and Dec. 1990 indicate that plants not receiving irrigation after early September were more water-stressed than those receiving water through November (Fig. 1). Similar differences between irrigation treatments in leaf water potential were obtained on 3 Dec. 1991 (data not shown). Naqvi et al. (1988) reported that water stress increases the tolerance of flower buds to freezing temperatures.

Seed yield. Seed yields in 1989 were low for all clones and irrigation treatments, averaging $40 \mathrm{~g} / \mathrm{plant}$, with many plants producing no seed (data not shown). The most important factor limiting yields was probably the 6 days of $-6 \mathrm{C}$ or lower during Dec. 1988. Also, because the planting was well-irrigatedin 1987 before treatments were initiated, plants in MT and DT likely had more water available in the lower depths of the soil profile in 1988 than in the following years and were not as water stressed in Winter $1988-89$ as in later winters.

Seed yields were higher the next 2 years, averaging $323 \mathrm{~g} / \mathrm{plant}$ in 1990 and $240 \mathrm{~g} /$ plant in 1991. In 1990, plants in MT and DT produced yields 3.5 times higher than those in WT (Table 3). Plants in MT had the highest yield in 1991. Although an average of $30 \%$ of flower buds survived in DT during Winter 1990-91 (Table 4), reduced growth in 1990 apparently limited the number of flower buds produced per plant and seed yield potential.

Seed yields of clones varied between years. In general, the best producing clones in DT in 1990 did not produce well in 1991. Clone 01 produced significantly higher yields in MT and DT than all other clones, except 06 in 1990 . Clone 21 produced the highest yield in 1991. The clones used in this study have not shown an alternate-year yielding habit when grown under optimum soil moisture conditions (unpublished data).

Flower bud survival did not always predict seed yield reliably, based on measurements in the upper canopy. For example, in WT in 1991, clone 03 had no apparent bud survival but produced 163 $\mathrm{g}$ of seed/plant, and clone 21 had only $6 \%$ survival but produced $407 \mathrm{~g}$ of seed/plant. Apparently, many flower buds on branches in the inner and lower parts of the canopy were not injured by freezing temperatures.
Table 4. Irrigation effects on flower bud survival on selected branches of six jojoba clones following the winters of $1989-90$ and $1990-91$.

\begin{tabular}{lrrrrrr}
\hline & \multicolumn{5}{c}{ Bud survival (\%) } \\
\cline { 2 - 7 } Irrigation & \multicolumn{5}{c}{ Clone } \\
\cline { 2 - 7 } treatment & 01 & 03 & 04 & 06 & 15 & 21 \\
\hline & & 0 & 5 & 2 & 0 & 0 \\
Wet & 2 & 0 & 24 & 41 & 0 & 19 \\
Medium & 3 & 14 & 18 & 33 & 32 & 69 \\
Dry & 36 & 33 & $1990-91^{y}$ & & & \\
& & 0 & 0 & 0 & 0 & 6 \\
Wet & 2 & 59 & 65 & 15 & 29 & 85 \\
Medium & 61 & 59 & 93 & 9 & 15 & 65 \\
Dry & 20 & 29 & 43
\end{tabular}

${ }^{\mathrm{z}}$ Interaction between irrigation and clones was significant at $P \leq 0.05$. LSD, at $P \leq 0.05$, is 10 for comparing clones within the same irrigation treatment, and is 12 for comparing clones for different irrigation treatments.

${ }^{\mathrm{y}}$ Interaction between irrigation and clones was significant at $P \leq 0.05$. LSD, at $P \leq 0.05$, is 10 for comparing clones within the same irrigation treatment, and is 8 for comparing clones for different irrigation treatments.

Weight per seed was highest in WT in 1990 and in WT and DT in 1991 (Table 5). Because of high flower bud mortality in WT each year and reduced growth in DT in 1990, there were fewer fruit and, thus, presumably, less competition among fruit for photosynthates.

Plants in all irrigation treatments had higher seed weights in 1991 than in 1990 (Table 5). The occurrence of a 49C maximum in June 1990 may have affected fruit filling adversely and reduced seed weights. In addition, MT and DT received more water during fruit filling in 1991 than in 1990.

Wax concentration and yield. Wax concentration was influenced more by irrigation treatment than by clone. The highest wax concentration was obtained in WT both years (Table 6). Wax concentration was lowest in DT in 1991, even though seed weight

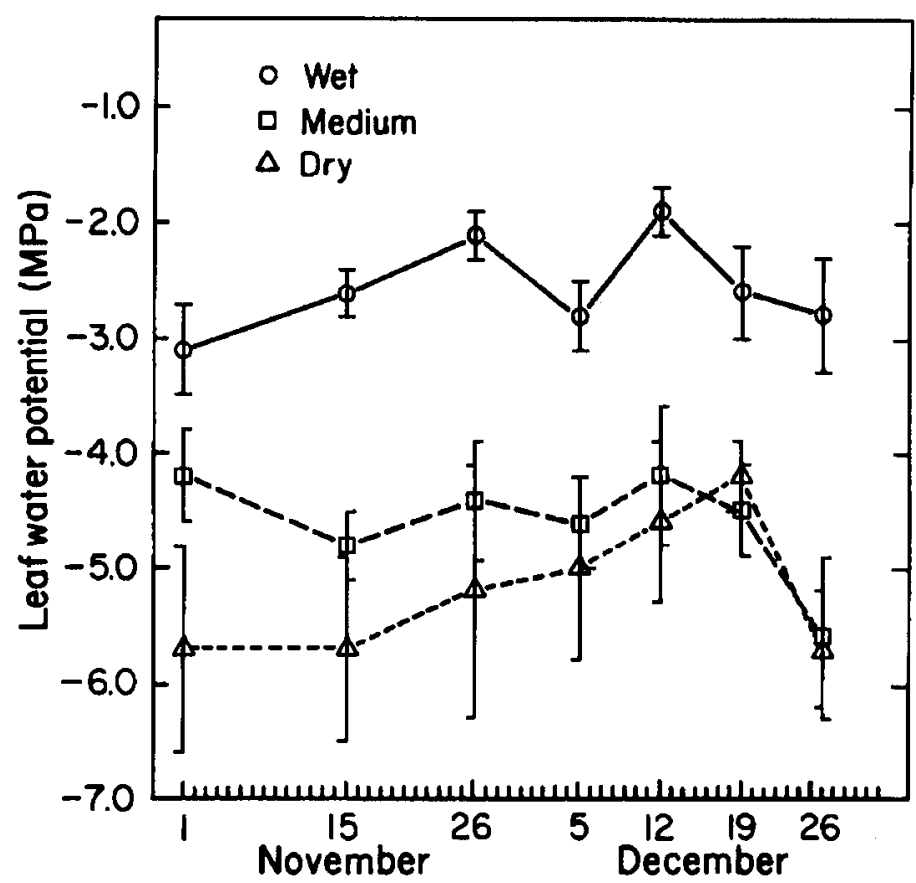

Fig. 1. Effect of irrigation treatments on jojoba midday leaf water potential between 1 Nov. and 26 Dec. 1990. Each datum is the mean for two clones. Vertical bars represent SD. 
Table 5. Irrigation effects on seed weight of four jojoba clones in 1990 and six clones in 1991.

\begin{tabular}{|c|c|c|c|c|c|c|}
\hline \multirow{3}{*}{$\begin{array}{l}\text { Irrigation } \\
\text { treatment }\end{array}$} & \multicolumn{6}{|c|}{ Wt per seed (g) } \\
\hline & \multicolumn{6}{|c|}{ Clone } \\
\hline & 01 & 03 & 04 & 06 & 15 & 21 \\
\hline \multicolumn{7}{|c|}{$1990^{2}$} \\
\hline Wet & 0.59 & --- & 0.77 & 0.80 & --- & 0.75 \\
\hline Medium & 0.45 & --- & 0.43 & 0.38 & --- & 0.35 \\
\hline Dry & 0.44 & --- & 0.57 & 0.43 & $\cdots$ & 0.36 \\
\hline \multicolumn{7}{|c|}{$1991^{y}$} \\
\hline Wet & 1.01 & 1.82 & 1.59 & 1.44 & 1.38 & 1.01 \\
\hline Medium & 0.73 & 0.79 & 0.70 & 0.73 & 0.88 & 0.66 \\
\hline Dry & 1.20 & 1.34 & 1.02 & 1.31 & 1.48 & 1.08 \\
\hline
\end{tabular}

${ }^{\mathrm{z}}$ Clones 03 and 15 were not included because not enough seeds were produced in the wet treatment to determine seed weight. Interaction between irrigations and clones was significant at $P \leq 0.05$. LSD, at $P \leq 0.05$, is 0.09 for comparing clones within the same irrigation treatment, and is 0.09 for comparing clones at different irrigation treatments.

y Interaction between irrigations and clones was significant at $P \leq 0.05$. LSD, at $P \leq 0.05$, is 0.20 for comparing clones within the same irrigation treatment, and is 0.22 for comparing clones at different irrigation treatments.

Table 6. Irrigation effects on seed wax concentration of four jojoba clones in 1990 and six clones in $1991 .^{z}$

\begin{tabular}{|c|c|c|c|c|c|c|}
\hline \multirow{3}{*}{$\begin{array}{l}\text { Irrigation } \\
\text { treatment }\end{array}$} & \multicolumn{4}{|c|}{ Wax concentration $(\%)$} & \multirow{3}{*}{$\begin{array}{l}1990^{\mathrm{v}} \\
\text { Mean }\end{array}$} & \multirow{3}{*}{$\begin{array}{l}1991^{x} \\
\text { Mean }\end{array}$} \\
\hline & \multicolumn{4}{|c|}{ Clone (1990) } & & \\
\hline & 01 & 04 & 06 & 21 & & \\
\hline$\overline{\text { Wet }}$ & 48.3 & 51.3 & 52.9 & 50.1 & 50.6 & 49.0 \\
\hline Medium & 44.6 & 43.3 & 44.1 & 42.8 & 43.7 & 46.8 \\
\hline Dry & 44.9 & 45.7 & 46.8 & 43.1 & 45.1 & 44.1 \\
\hline Mean & 45.9 & 46.8 & 47.9 & 45.3 & & \\
\hline
\end{tabular}

${ }^{\mathrm{z}}$ Clones 03 and 15 were not included because not enough seeds were produced in the wet treatment in 1990 to determine wax concentration.

$\mathrm{y}_{\mathrm{LSD}}, P \leq 0.05$, for comparing irrigation treatment means $=2.3$ and for comparing clones means $=1.6$.

$\mathrm{x}_{\mathrm{LSD}} P \leq 0.05$ for comparing irrigation treatment means $=2.1$. Means were for six clones.

Table 7. Irrigation effects on wax yield of four jojoba clones in 1990 and six clones in 1991.

\begin{tabular}{|c|c|c|c|c|c|c|c|}
\hline \multirow{3}{*}{$\begin{array}{l}\text { Irrigation } \\
\text { treatment }\end{array}$} & \multicolumn{7}{|c|}{ Wax yield (kg/ha) } \\
\hline & \multicolumn{6}{|c|}{ Clone } & \multirow[b]{2}{*}{ Mean } \\
\hline & 01 & 03 & 04 & 06 & 15 & 21 & \\
\hline \multicolumn{8}{|c|}{$1990^{2}$} \\
\hline Wet & 136 & --- & 208 & 182 & -- & 83 & 152 \\
\hline Medium & 573 & --- & 189 & 494 & --- & 181 & 359 \\
\hline Dry & 542 & --- & 213 & 376 & --- & 241 & 343 \\
\hline Mean & 417 & --- & 203 & 351 & --- & 168 & \\
\hline \multicolumn{8}{|c|}{$1991^{y}$} \\
\hline Wet & 154 & 136 & 9 & 55 & 7 & 340 & 117 \\
\hline Medium & 397 & 343 & 307 & 124 & 380 & 579 & 355 \\
\hline Dry & 19 & 129 & 127 & 12 & 146 & 172 & 101 \\
\hline Mean & 190 & 203 & 148 & 64 & 178 & 364 & \\
\hline
\end{tabular}

${ }^{\overline{ }}$ Clones 03 and 15 were not included because not enough seeds were produced in the wet treatment to determine wax concentration. Interaction between irrigations and clones was significant at $P \leq 0.05$. LSD, $P \leq 0.05$, for comparing clones within the same irrigation treatment $=168$, and for comparing clones at different irrigation treatments $=288$.

$\mathrm{y}_{\mathrm{LSD}, P} \leq 0.05$, for comparing irrigation treatment means $=132$, and for comparing clones $=128$.

and seed yield were similar to that in WT. The limited growth that occurred in the dry plots in 1990 possibly had an adverse effect on wax production in 1991.

The effect of irrigation treatments was not as pronounced on wax yield as on seed yield. Nevertheless, wax yield in MT and DT was 2.3 times higher than in WT in 1990 (Table 7). In 1991, MT had significantly higher wax yield than WT and DT. Wax yields of clones varied among years similarly to seed yields. In 1990, clone 01 produced significantly higher yields in MT and DT than all other clones, except 06. Clone 21 produced the highest wax yield in 1991 . 
Overview. In 2 of 3 years, this study's management system withheld irrigation water from jojoba from early September through the winter and was effective in improving flower bud survival and seed and wax yields following winters with damaging frost. Having jojoba plants in a water-stressed condition going into the winter apparently improves the chances of flower buds surviving freezing temperatures. An added advantage of this irrigation system is that fall irrigations are eliminated, and the crop's water requirements are lowered.

Withholding irrigations for part of the growing season to improve flower bud survival has, however, the disadvantage of reducing branch growth. Plower buds appear only on the current season's growth, and when that growth is reduced, the number of flower buds generally is reduced proportionately. In a year following a winter during which freezing temperatures were not a problem, seed yields would be highest for plants that were irrigated throughout the season. Therefore, an irrigation system using fall and winter water stress to improve flower bud survival has the greatest potential for plantations already established in areas that are subjected regularly to freezing damage.

The clones we used differed in their response to irrigation in terms of frost injury and seed and wax yields. Part of the solution to the frost problem in jojoba must include the development of frost-resistant cultivars.

\section{Literature Cited}

Ceccardi, T.L., H.H. Naqvi, and I.P. Ting. 1990. Physiological responses of jojoba to drought and frost stress, p. 47-52. In: H.H. Naqvi, A. Estalai, and I.P. Ting (eds.). Proc. First Intl. Conf. New Ind. Crops and Prod. Riverside, Calif., 8-12 Oct. 1990. Dunstone, R.L. 1988. The reproductive cycle in jojoba, p. 50-59. In: A.R. Baldwin (ed.). Proc. Seventh Intl. Conf. Jojoba and Its Uses. Phoenix, Ariz., 17-22 Jan. 1988.

Hogan, L. and D.A. Palzkill. 1983. Importance of selection and evaluation of vegetatively propagated jojoba before commercial release, p. 177-179. In: A. Elias-Cesnik (ed.). Proc. Fifth Intl. Conf. Jojoba and Its Uses. Tucson, Ariz., 1115 Oct. 1982.

Naqvi, H.H., G. Goldstein, C. Ratnayaka, T. Ceccardi, and I.P. Ting. 1988. Jojoba breeding and agronomic investigations at U.C. Riverside, p. 395-409. In: A.R. Baldwin (ed.). Proc. Seventh Intl. Conf. Jojoba and Its Uses. Phoenix, Ariz., 1722 Jan. 1988.

Nerd, A. and A. Benzioni. 1985. Effects of water deficits and of fruit filling on vegetative growth of jojoba, p. 193-200. In: J. Wisniak and J. Zabicky (eds.). Proc. Sixth Intl. Conf. Jojoba and Its Uses. Ben-Gurion Univ., Beer-Sheva, Israel, 21-26 Oct. 1984..

Palzkill, D.A., M.H. Younes, and L. Hogan. 1989. AT-1310, AT-1487, and AT3365: Clonal jojoba germplasm selected for horticultural use. HortScience 24:526-527.

Yermanos, D.M. 1983. Performance of jojoba under cultivation between 1973-1982: Information developed at the University of California, Riverside, p. 197-211. In: A. Elias-Cesnik (ed.). Proc. Fifth Intl. Conf. Jojoba and Its Uses. Tucson, Ariz., 11-15 Oct. 1982. 